\title{
Modificação endometrial intensa induzida por tamoxifeno no tratamento do câncer de mama
}

Intense endometrial chance induced by tamoxifen for breast cancer treatment

Ruffo Freitas-Junior ${ }^{1}$, Maria Virgínia Thomazini², Amaurillo Monteiro de Oliveira',

Francisco de Assis Freire Dourado ${ }^{1}$, Glória Jabur Bittar Oton 3

Paciente de 69 anos, do sexo feminino, há 3 anos foi submetida à cirurgia de ressecçâo de mama direita com linfadenectomia axilar. $\mathrm{O}$ exame histopatológico da lesão revelou carcinoma ductal infiltrante, grau II de anaplasia. A imunoistoquímica mostrou RE (+), RP (+), HER2 escore 0 e Ki-67 (+) em 50\% das células neoplásicas. Dos nove linfonodos axilares ressecados, dois estavam comprometidos. A paciente foi submetida à quimioterapia adjuvante (FAC 6 ciclos), seguida por radioterapia. Na sequência ela iniciou endocrinoterapia adjuvante com tamoxifeno.

Após 20 meses do início do uso de tamoxifeno, a paciente queixou-se de um episódio único de discreta perda sanguínea transvaginal. A ultrassonografia transvaginal mostrou endométrio heterogêneo com textura sólida e cística, com bordas e contornos bem definidos e acentuado espessamento de $29 \mathrm{~mm}$, sem halo endometrial ou sinais de infiltração do miométrio (Figura 1).

Levando-se em consideração o espessamento endometrial intenso, associado ao sangramento transvaginal, procedeu-se uma curetagem uterina, em que foi observada a saída de material constando de vários fragmentos de tecido, de forma irregular, coloraçáo hemorrágica e consistência macia, medindo $0,7 \times 0,7 \times 0,6 \mathrm{~cm}$ o conjunto. A histologia revelou material hemorrágico com glândulas recobertas por epitélio colunar simples e ausência de hiperplasia ou de malignidade (Figuras 2 e 3).

A intenção deste relato foi mostrar que espessamentos de $15 \mathrm{~mm}$, ou mesmo mais acentuados, são achados frequentes por meio de ultrassonografia transvaginal em usuárias de tamoxifeno. Assim, ao contrário das mulheres pós-menopáusicas, que devem ter seu endométrio explorado diante de um espessamento endometrial maior que $5 \mathrm{~mm}$, para as usuárias de tamoxifeno, a manipulação endometrial passa a ser desnecessária, por aumentar a possibilidade de lesôes iatrogênicas, sem gerar benefício ao diagnóstico do câncer de endométrio.

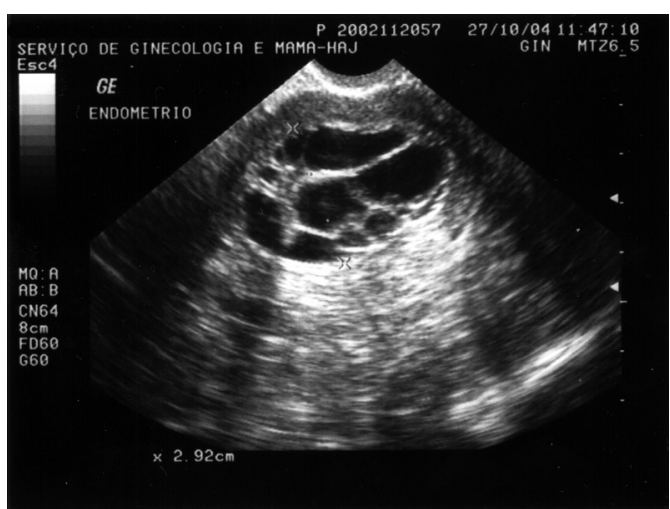

Figura 1. Imagem de ultrassonografia transvaginal mostrando endométrio com textura sólido-cística medindo $29 \mathrm{~mm}$ de espessura

Estudo realizado nos Serviços de Ginecologia \& Mama e de Anatomia Patológica do Hospital Araújo Jorge da Associação de Combate ao Câncer em Goiás - Goiânia (G0), Brasil.

'Serviço de Ginecologia e Mama do Hospital Araújo Jorge da Associação de Combate ao Câncer em Goiás - Goiânia (GO), Brasil. 2Universidade Estadual de Campinas (UNICAMP); Liga da Mama da Faculdade de Medicina da Universidade Federal de Goiás (UFG) Goiânia (GO), Brasil.

${ }^{3}$ Serviço de Anatomia Patológica do Hospital Araújo Jorge da Associação de Combate ao Câncer em Goiás - Goiânia (G0), Brasil. Endereço para correspondência: Ruffo Freitas-Junior - Rua 239, 181 - Setor Universitário - CEP 74650-070 - Goiânia (GO), Brasil - 


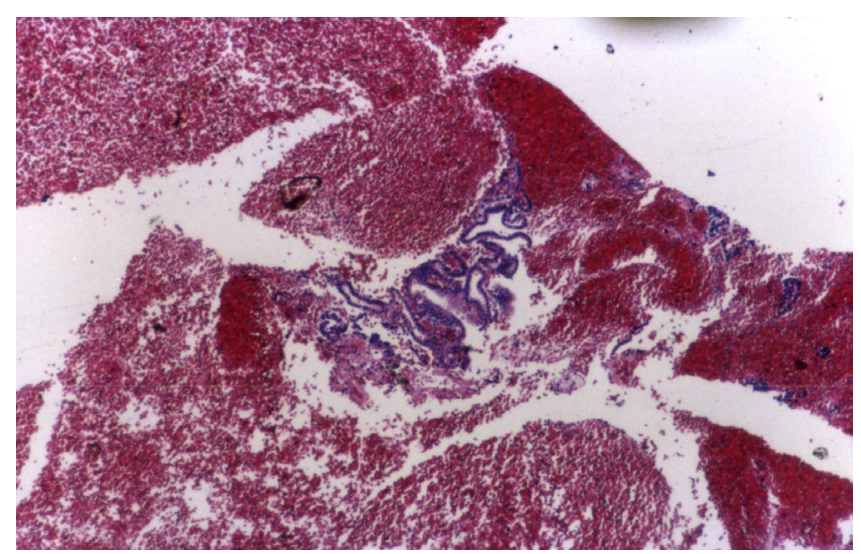

Figura 2. Endométrio com poucas glândulas cobertas por epitélio colunar simples e ausência de hiperplasia ou malignidade (Hematoxilina-eosina 100x)

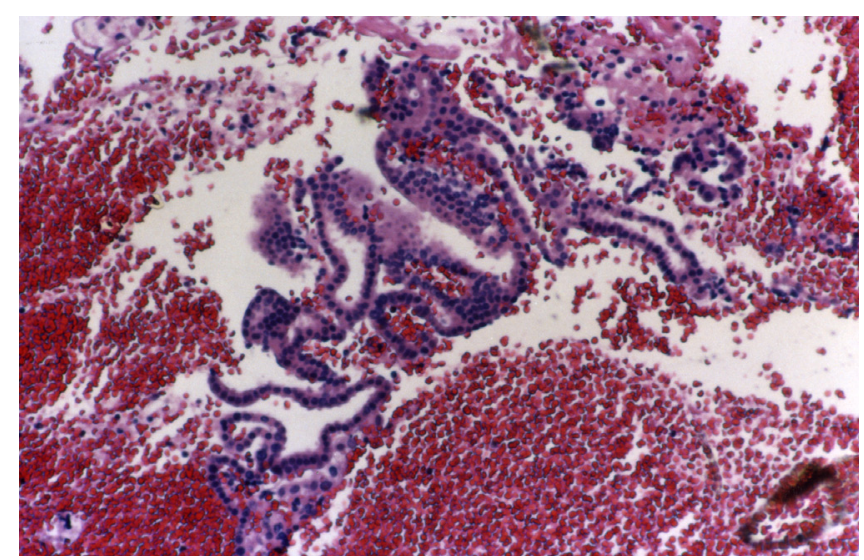

Figura 3. Detalhe do endométrio com epitélio colunar simples (Hematoxilinaeosina 400x) 